\title{
Childhood Trichotillomania with a typical Treatment Response: A Case Report
}

\section{Mrinmay, Das}

Department of Psychiatry, Government Medical College, Haldwani Uttarakhand, India

*Corresponding author: Mrinmay Das, MBBS, MD, Department of Psychiatry, Government Medical College, Haldwani Uttarakhand, India, 263139, E-mail: mrinmaysmail@gmail.com

\begin{abstract}
Trichotillomania once was considered as a rare disorder but now it is recognized as a psychiatric illness that is not as rare as previously thought. Standard treatment guideline of this disorder, especially for children is not available till the present date. In this report, a case of childhood trichotillomania, its various diagnostic possibilities and successful treatment with Risperidone in a child has been described.
\end{abstract}

Keywords: Trichotillomania; Childhood onset; Risperidone
Received Date: December 10, 2015

Accepted Date: October 28, 2016

Published Date: November 2, 2016

Citation: Das, M. Childhood Trichotillomania with a typical Treatment Response: A Case Report. (2016) Int J Neurol Brain Disord 3(4): 1- 2.

DOI: $10.15436 / 2377-1348.16 .716$

\section{Introduction}

French dermatologist, François Henri Hallopeau was the first to describe a case of self-inflicted depilation of scalp and he coined the term Trichotillomania in 1989. This word is derived from Greek words: tricho- (hair), tillo (pull), and mania (madness). The term trichotillomania is misleading because the suffix "mania" implies the presence of a serious psychiatric disorder. Even after 100 years of recognising the disease, etiology, natural history and treatment is not fully clear. However, it is suggested that the adult type of trichotillomania is associated with greater psychopathology than that seen in childhood ${ }^{[1-3]}$.

According to the Diagnostic and Statistical Manual of mental disorders (fifth edition) ${ }^{[4]}$, in general population, the twelve month prevalence of trichotillomania in adolescents and adult is $1-2 \%$. Trichotillomania appears to be more frequent in females than in males, at a ratio of approximately 10:1. The female preponderance may be due to women's greater willingness to seek treatment for cosmetic issue. Hair pulling is seen in all age groups, even in infants though it is more often seen in the first two decades of life, especially in female adolescents.

ICD 10 (International Classification of Diseases $10^{\text {th }}$ revision ${ }^{[15]}$ has classified trichotillomania in habit and impulse disorder where as DSM-V (Diagnostic and Statistical Manual of Mental Disorders, Fifth Edition $)^{[4]}$ puts it under obsessive compulsive and related disorders. Meyer and Haag ${ }^{[6]}$ reported trichotillomania's association with stressful situations. Major depression, dysthymia, anxiety, borderline personality, psy- chosis, academic problems and over-concern with weight have also been observed in association with trichotillomania ${ }^{[7]}$. Hair pulling that occurs in infancy and early childhood appears to be more likely to remit spontaneously or with minimal treatment ${ }^{[7]}$. Oranje et $\mathrm{al}^{[1]}$, reported trichotillomania in childhood starting as a "habit disorder". It is often seen in association with thumb sucking, nail biting, and nose picking.

No single modality has been established as definitive effective treatment approach. Habit reversal training (HRT) is a behaviourally based treatment approach designed to treat trichotillomania. But its utility in early childhood is limited. Many drugs has been reported to be effective in this condition, commonly antidepressant, combination of antidepressant and antipsychotics, even hormonal treatment has been reported in cases, depending upon the associated co-morbid illnesses ${ }^{[7]}$.

\section{Case History}

A 44 months- old girl was referred from Paediatrics OPD (outpatient department) to the Psychiatry OPD with complain of hair loss in the left fronto-parieto-temporal region around $4 \mathrm{~cm} \mathrm{x} 4 \mathrm{~cm}$-area. Parents reported that they had noticed gradual loss of hair on the said area for about 6 months; on vigilance they found that the child would pull hair from that site. On being asked the child could not give any explanation and could only say that she would experience 'uneasiness' before pulling 
hair.

Parents also reported that for last one month the frequency of hair pulling had increased significantly to the extent that the area had become totally hairless and ugly looking. This made parents more concerned about the child.

On being asked, parents reported that there was change in the child's behavior for last one month. She was more active as compared to her previous self. She would not sit quietly while studying or watching television unlike her previous self, and was easily irritable and fidgety. Though there were frequent breaks in her sleep at night, she would not feel sleepy during day time. Though she would take food routinely, the intake was decreased. Parents reported that there was no significant weight loss in the child, but they gave history of constipation for last 10 days. The patient never made an attempt to eat the pulled out hair.

The patient belongs to nuclear family of lower middle socio-economic status. She is younger among two siblings. She was born normally at full term with uneventful antenatal period, had achieved normal mile-stones of development and had no history of neurotic traits initially. No history of nail biting and thumb sucking was present. Family history of hair pulling from head and eye brow to that extent of baldness was present in her cousin sister - no further details were available. No history of discordance among the family members was present.

Physical examination of the patient revealed an area of baldness over the left fronto-parieto-temporal region. In rest of the scalp, hairs were very short (trimmed). General and systemic examinations did not show any pathology. Her psychomotor activities were increased. There was no evidence of hallucination or delusion. Patient had no insight into her problems.

On routine examination, haemogram, liver function tests, kidney function tests and electrocardiography were normal. Thyroid Function Tests (TFT) showed increased Thyroid Stimulating Hormone (TSH) $(5.61 \mu \mathrm{IU})$ with normal T3 \& T4 levels. Paediatrician's opinion was taken for deranged TFT but no active intervention was advised as it was subclinical hypothyroidism. Patient was referred to Dermatologist, who too did not advise any treatment after examining the patient and referred her back to Psychiatry OPD.

Patient was treated with $0.25 \mathrm{mg}$ of Risperidone and dietary modifications were advised for constipation. After one week of follow up parents reported some improvement in her over-activity, sleep disturbance, irritability, fidgeting and also improvement in frequency of hair pulling. The dose of Risperidone was increased to $0.5 \mathrm{mg}$. In the follow-up examinations over the next three months there was significant improvement - the bald area was covered by small hair as well as other symptoms.

\section{Discussion}

The present case -44 months old girl child presenting with history of hair pulling and bald patch - responded well to Risperidone. The relationship between anxiety and hair pulling is difficult to establish in this patient. However, in this reported case there is some evidence of anxiety characterised by patient's complain of some "uneasy feeling" before the hair pulling. It may be possible that because of age factor, the patient could not properly describe anxiety symptoms. Also, hyperactivity, easy irritability, fidgeting may be manifestations of her anxiety ${ }^{[8]}$. These symptoms might also lead us to think of the diagnosis of Mania or ADHD.

Therefore, clinical features of reported patient do not categorically fit for trichotillomania or mania or Attention Deficit Hyperactivity Disorder. Also, no definite guideline for the management of trichotillomania in early childhood is available till date. Considering that both of manic symptoms and ADHD would respond to antipsychotics, Risperidone was started.

Subclinical hypothyroidism might have been an associated co-morbid illness in this patient, but hypothyroidism is associated with passive loss of hair not with active pulling of hair [9]. Also, in this case the thyroid status remained same after two months on repeat examination though there was improvement in pulling of hair. Thus, thyroid disorder as a cause for hair loss in this patient was ruled out.

There is evidence for a genetic vulnerability to trichotillomania and more common in individual with Obsessive Compulsive Spectrum Disorder and their first degree relatives ${ }^{[7,10]}$. In this case one of paternal cousin sister, aged -12 years, has features suggestive of trichotillomania, though that case was not accessible to the authors.

Considering the above case and its significant improvement with prescription of an antipsychotic, it can be said that trichotillomania in children might be associated other differentials. Therefore, a broad perspective might be required for successful treatment.

\section{References}

1. Oranje, A.P., Peere-Wynia, J.D., De, Raeymaker, D.M. Trichotillomania in Childhood. (1986) J Am Acad Dermatol 15(4 Pt 1): 614-619.

2. Hautmann, G., Hercogova, J., Lotti, T. Trichotillomania. (2002) J Am Acad Dermatol 46(6) :807-821.

3. Byrd, M.R., Richards, D.F., Hove, G., et al. Treatment of early onset hair pulling as a simple habit. (2002) Behav Modif 26(3) :400-411.

4. Diagnostic and Statistical Manual of Mental Disorders. (2013) 5th ed. American Psychiatric Association: p.251.

5. The ICD-10 Classification of Mental and Behavioural Disorders: Clinical Descriptions and Diagnostic Guidelines. (1992) World Health Organisation: p. 167.

6. Meyer, A.E., Haag, A. Psychosomatics of Trichotillomania and Related States or Disorders. (1984) Psychother Psychosom 42: 119 - 123. 7. Koran, L.M. Obsessive-Compulsive and Related Disorders in Adults: A Comprehensive Clinical Guide. (1999) Cambridge: Cambridge University Press.

8. Adam, B.S., Kashani, J.H. Trichotillomania in children and adolescents: review of the literature and case report. (1990) Child Psychiatry Hum Dev. 20(3):159-168.

9. Jameson, L.J., Weetman, A.P. Disorders of the Thyroid Gland. In: Fauci A, Braunwald E, Kasper D, Hauser S, Longo D, Jameson LJ, Loscalzo J, editors. Harrison's Principles of Internal Medicine. 17th ed. (2008) New York: McGraw-Hill.

10. Stein, D.J., Hollander, E., Rothbaum, B.O. 2nd ed.Text book of Anxiety Disorders. (2009) Washington,DC: American Psychiatric Publishing, Inc..
Online ISSN: $2377-1348$

Journal Title: International Journal Neurology and Brain Disorders Journal Short Name: Int J Neurol Brain Disord
Ommega Online Publishers

E-mail: neurology@ommegaonline.com

Website: www.ommegaonline.org 